\title{
Homocysteine inhibits neoangiogenesis in mice through blockade of annexin A2-dependent fibrinolysis
}

\author{
Andrew T. Jacovina, ${ }^{1}$ Arunkumar B. Deora, ${ }^{1}$ Qi Ling, ${ }^{2}$ M. Johan Broekman, ${ }^{3,4}$ Dena Almeida, ${ }^{1}$ \\ Caroline B. Greenberg, ${ }^{1}$ Aaron J. Marcus, ${ }^{3,4}$ Jonathan D. Smith, ${ }^{5}$ and Katherine A. Hajjar ${ }^{1}$

\begin{abstract}
1Department of Cell and Developmental Biology, Weill Cornell Medical College, New York, New York, USA. 2Department of Psychiatry, University of Connecticut School of Medicine, Farmington, Connecticut, USA. ${ }^{3}$ Department of Medicine,

Weill Cornell Medical College, New York, New York, USA. ${ }^{4}$ Thrombosis Research Laboratory, VA New York Harbor Healthcare System New York, New York, USA. ${ }^{5}$ Department of Cell Biology, Lerner Research Institute/NC10, Cleveland, Ohio, USA.
\end{abstract}

\begin{abstract}
When plasma levels of homocysteine (HC), a thiol amino acid formed upon methionine demethylation, exceed $12 \mu \mathrm{M}$, individuals are at increased risk of developing large vessel atherothrombosis and small vessel dysfunction. The annexin A2 complex (termed "A2") is the cell surface coreceptor for plasminogen and TPA and accelerates the catalytic activation of plasmin, the major fibrinolytic agent in mammals. We previously showed that HC prevents A2-mediated, TPA-dependent activation of plasminogen in vitro by disulfide derivatization of the "tail" domain of A2. We also demonstrated that fibrinolysis and angiogenesis are severely impaired in A2-deficient mice. We now report here that, although hyperhomocysteinemic mice had a normal coagulation profile and normal platelet function, fibrin accumulated in their tissues due to reduced perivascular fibrinolytic activity and angiogenesis was impaired. A2 isolated from hyperhomocysteinemic mice failed to fully support TPAdependent plasmin activation. However, infusion of hyperhomocysteinemic mice with fresh recombinant A2, which localized to neoangiogenic endothelial cells, resulted in normalization of angiogenesis and disappearance of peri- and intravascular fibrin. We therefore conclude that hyperhomocysteinemia impairs postnatal angiogenesis by derivatizing A2, preventing perivascular fibrinolysis, and inhibiting directed endothelial cell migration. These findings provide a mechanistic explanation for microvascular dysfunction and macrovascular occlusion in individuals with hyperhomocysteinemia.
\end{abstract}

\section{Introduction}

Endothelial cells express plasminogen activators, their receptors, and their inhibitors, all of which are key elements in the fibrinolytic surveillance mechanism of blood vessels (1). Together with an array of endothelial cell surface natural anticoagulants, this system is central to the maintenance of blood fluidity. While TPA is secreted by resting microvascular endothelial cells in many vascular beds, urokinase is produced by perturbed endothelial cells in settings such as wound repair and inflammation $(2,3)$. Cultured endothelial cells specifically bind both TPA and its substrate, plasminogen (4-6), via surface expression of the calcium-dependent, phospholipid-binding protein annexin A2 (herein referred to as "A2") (7). A2 is a member of a large, multi-phylum superfamily of calcium-dependent, phospholipid-binding proteins $(8,9)$. Upon interaction with plasminogen and TPA, purified A2 confers a 60-fold increase in the efficiency of TPA-dependent plasmin generation (10). Complete deficiency of A2 in mice is associated with microvascular fibrin deposition and impaired clearance of injury-induced arterial thrombi (11). In addition, Anxa $2^{-/-}$mice show striking defects in postnatal angiogenesis, suggesting a mechanistic association between A2-based endothelial cell fibrinolytic activity and angiogenic potential.

Homocysteine (HC) is a thiol-containing amino acid intermediate that is generated during the conversion of methionine to cysteine

Authorship note: Andrew T. Jacovina, Arunkumar B. Deora, and Qi Ling contributed equally to this work.

Conflict of interest: The authors have declared that no conflict of interest exists. Citation for this article: J. Clin. Invest. 119:3384-3394 (2009). doi:10.1172/JCI39591.
(12). Due to the increased length of its R-group carbon chain compared to that of cysteine, the HC thiolate displays increased nucleophilic reactivity compared with that of the cysteine thiolate (13). HC circulates in normal human plasma at concentrations of 5 to $12 \mu \mathrm{M}$ (14-16). Hyperhomocysteinemia is associated with mutations in genes encoding cystathionine- $\beta$ synthase, methionine synthase, and 5,10-methylenetetrahydrofolate reductase. It also occurs in association with environmental factors such as gender, age, and diet, in which deficiency of folate, vitamin $B_{6}$, and vitamin $B_{12}$ appear to be primary determinants $(15,17,18)$. Previous studies have linked mild to moderate hyperhomocysteinemia with macrovascular occlusion related to venous thromboembolism as well as coronary, cerebrovascular, and peripheral atherosclerosis (14). More recent studies have revealed an association between hyperhomocysteinemia and microvasculopathy, particularly cerebral small vessel disease (19). Despite these associations, the molecular mechanisms underlying HC-associated vascular disorders have not been clearly defined (20).

We previously demonstrated that the binding of TPA to A2 requires residues 7-12 (LCKLSL) of the A2 aminoterminal "tail" domain (21). Furthermore, we showed that the TPA-A2 interaction on the surface of endothelial cells is inhibited by pre-incubation with HC (22). In this reaction, it appears that uptake of HC and its condensation with the free sulfhydryl of cysteine 8 of A2 may require several hours to reach levels that are functionally significant. This modification of A2 decreases its ability to support plasminogen activation (21-23). From these studies, we concluded that HC might perturb the intrinsic fibrinolytic potential of the endothelial cell by selectively blocking TPA binding to A2. 


\section{Table 1}

HC levels, body weight, and hematologic data

\begin{tabular}{|c|c|c|c|c|c|}
\hline Parameter & Chow diet & Gly diet & Met diet & $n$ & $P A$ \\
\hline Plasma HC ( $\mu \mathrm{M})$ & $11.3 \pm 1.0$ & $17.3 \pm 1.4$ & $69.5 \pm 5.9$ & 11 & 0.002 \\
\hline Body weight (g) & $28.7 \pm 0.7$ & $28.9 \pm 0.7$ & $23.6 \pm 0.5$ & 10 & 0.00003 \\
\hline Hematocrit $(\%)$ & $43.6 \pm 0.6$ & $48.0 \pm 0.4$ & $44.4 \pm 1.0$ & 3 & NS \\
\hline White blood cells $(103 / \mu l)$ & $8.61 \pm 2.20$ & $7.62 \pm 0.63$ & $10.0 \pm 2.0$ & 3 & NS \\
\hline Platelet count $\left(10^{3} / \mu \mathrm{l}\right)$ & $806 \pm 53$ & $784 \pm 69$ & $905 \pm 6$ & 3 & NS \\
\hline \multicolumn{6}{|l|}{ Platelet aggregometry } \\
\hline $\operatorname{ADP}(2.5 \mu \mathrm{M})$ & $210 \pm 11$ & $215 \pm 43$ & $211 \pm 8$ & 5 & NS \\
\hline $\operatorname{ADP}(10 \mu \mathrm{M})$ & $347 \pm 22$ & $295 \pm 9$ & $300 \pm 31$ & 4 & NS \\
\hline Collagen $(1 \mu \mathrm{g} / \mathrm{ml})$ & $168 \pm 26$ & $212 \pm 40$ & $190 \pm 31$ & 4 & NS \\
\hline Collagen $(5 \mu \mathrm{g} / \mathrm{ml})$ & $257 \pm 15$ & $257 \pm 86$ & $258 \pm 25$ & 3 & NS \\
\hline Fibrinogen (mg/dl) & $413 \pm 14$ & $433 \pm 5$ & $436 \pm 4$ & 3 & NS \\
\hline D-dimer (ng/ml) & $7.0 \pm 2.4$ & $5.9 \pm 1.9$ & $7.1 \pm 1.8$ & 14 & NS \\
\hline Plasma clotting time (min) & $5.9 \pm 0.5$ & $7.8 \pm 0.7$ & $6.2 \pm 0.6$ & 6 & NS \\
\hline Half-maximal plasma clot lysis time (min) & $11.8 \pm 0.8$ & $10.7 \pm 0.7$ & $10.7 \pm 0.4$ & 4 & NS \\
\hline PN/anti-PN (ng/ml)C & $106 \pm 5.1$ & $98 \pm 12$ & $99 \pm 0.3$ & 9 & NS \\
\hline
\end{tabular}

AGly diet versus Met diet. ${ }^{B}$ Area under the curve units. ${ }^{C}$ The complex formed by plasmin and its inhibitor, anti-plasmin. Values shown represent mean \pm SEM for the $n$ value given.

Angiogenesis is the process by which new blood vessels arise from pre-existing vasculature. It entails a complex series of steps whereby activated endothelial cells dissociate from their underlying matrix, migrate toward a chemotactic stimulus, and proliferate $(24,25)$. Endothelial cells utilize MMPs to migrate through matrix barriers (26). In the mouse, MMP-3 and MMP-13 are directly activated by the serine protease, plasmin, and MMP-3 can subsequently activate MMP-9 (27). Thus, activation of the fibrinolytic system may initiate an extended, matrix-remodeling proteolytic cascade (28).

In the present study, we examine the effects of $\mathrm{HC}$ on postnatal angiogenic responses in vivo. In the setting of diet-induced hyperhomocysteinemia, mice developed microvascular fibrin accumulation, reduced perivascular fibrinolysis, and increased susceptibility to arterial thrombosis. A2 isolated from hyperhomocysteinemic mice under non-reducing conditions, furthermore, failed to bind TPA and did not support plasminogen activation. At the same time, the angiogenic response was reduced, and VEGF-directed migration of endothelial cells pretreated with HC was blunted. Importantly, angiogenic failure in the corneal pocket assay was accompanied by intra- and perivascular fibrin accumulation. Infusion of recombinant A2 associated specifically with neovascular endothelial cells restored the angiogenic response and inhibited fibrin accumulation. Interestingly, diet-induced hyperhomocysteinemia did not depress corneal angiogenesis beyond that observed in Anxa2 $2^{--}$mice. This suggested that the antiangiogenic effect of HC is exerted via a pathway that is dependent upon A2. Impairment of fibrinolysis and angiogenesis in the hyperhomocysteinemic mouse may be an etiologic factor underlying the role of $\mathrm{HC}$ as a risk factor for thrombosis, atherosclerosis, and small vessel disease.

\section{Results}

Nutritional effects of a high-methionine diet. In mice placed on a highmethionine (Met) diet, plasma HC levels were, on average, 4-fold higher than those observed in mice on the control high-glycine (Gly) diet and 6-fold higher than those in mice fed standard chow $(69.5 \pm 5.9$ vs $17.3 \pm 1.4$ vs $11.3 \pm 1.0 \mu \mathrm{M}$, respectively, mean $\pm \mathrm{SEM}$, $n=11, P=0.002$ for Gly vs. Met vs. chow) (Table 1 ). The 1.5 -fold increase in HC levels in mice on the Gly diet versus those on stan- dard chow diet was most likely due to its lower folic acid content ( 1.98 vs. $3.0 \mathrm{mg} / \mathrm{kg}$ chow). Mice on the Met diet, in addition, exhibited an $18 \%$ reduction in body mass compared with those on the Gly diet, even though food consumption was equivalent.

Hematologic parameters in hyperhomocysteinemic mice. In mice on the Gly diet, hematocrits were slightly higher than those in mice on either the chow or Met diets, possibly reflecting mild dehydration. At the same time, however, we found no significant difference in leukocyte and platelet counts or plasma fibrinogen levels among the 3 groups (Table 1). Platelet reactivity in platelet-rich plasma in response to either 2.5 or $10 \mu \mathrm{M}$ ADP or 1 or $5 \mu \mathrm{g} / \mathrm{ml}$ collagen was also equivalent among the 3 groups. In addition, D-dimer and plasma clotting time, a reflection of the rate of thrombin generation, were not significantly altered. Finally, TPA-dependent plasma clot lysis time and circulating plasmin-antiplasmin complex concentrations were equivalent among the 3 experimental groups, indicating that plasma components associated with fibrinolytic function were unaltered.

Hyperhomocysteinemia and vascular fibrinolysis. Tissues from mice receiving chow, Gly, or Met diets were examined next. Immunohistologic analysis of sections of renal tissue revealed only minimal fibrin associated with glomeruli from mice fed normal chow or Gly diets but abundant fibrin associated with glomeruli from mice fed a Met diet (Figure 1, A-C). Sections of heart and lung tissue showed a similar pattern, with significant fibrin staining detected only in samples from Met diet-fed mice (Figure 1, D-I). In addition, casein overlay of frozen lung sections from mice fed the Met diet revealed perivascular zones of lysis that were significantly reduced in area (Figure $1 \mathrm{~L} ; 3,480 \pm 360 \mu \mathrm{m}^{2}$; mean $\pm \mathrm{SEM}$, $n=10)$ compared with those in overlays of tissue from mice fed either a chow diet (Figure 1J; 5,440 $\pm 600 \mu \mathrm{m}^{2}$; mean \pm SEM, $n=10$, $P<0.001$ ) or Gly diet (Figure $1 \mathrm{~K} ; 7160 \pm 480 \mu \mathrm{m}^{2}$; mean \pm SEM, $n=10, P<0.001)$. These data suggested a deficiency of vascular fibrinolysis in mice on the Met diet.

To further explore fibrinolytic function in the 3 groups of mice, we studied injury-induced thrombosis in the carotid artery. We used the $\mathrm{FeCl}_{3}$ vascular injury model, which has been used extensively to define thrombotic tendencies in mice with fibrinolytic 

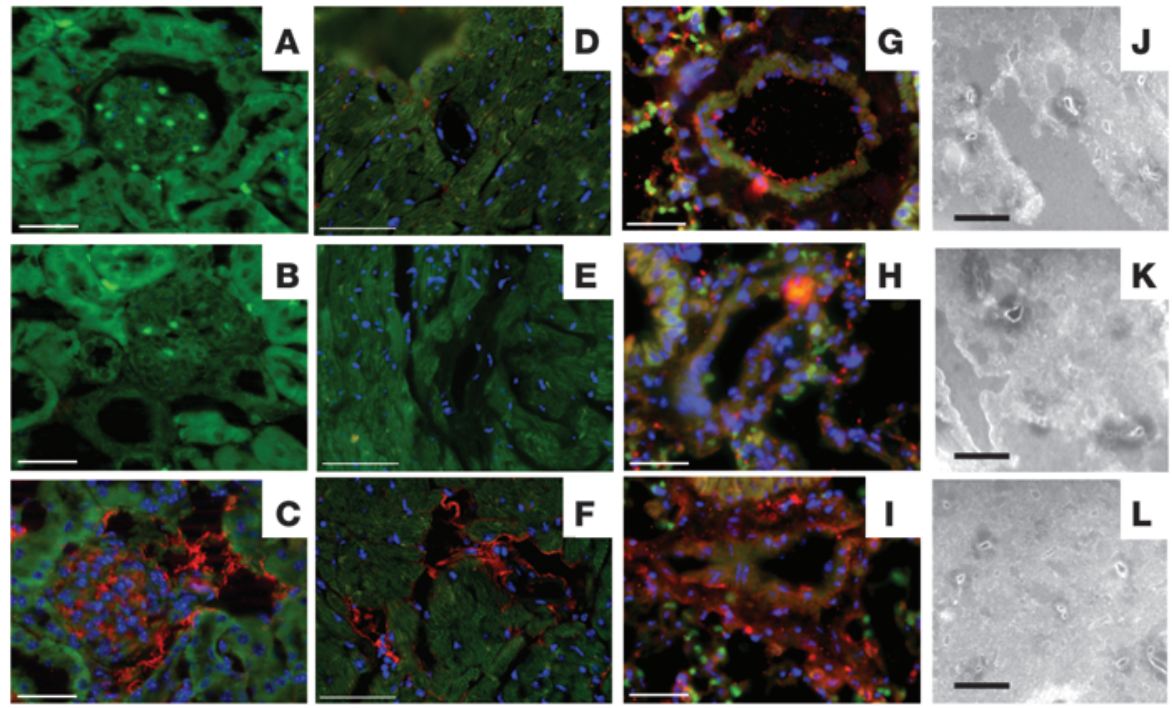
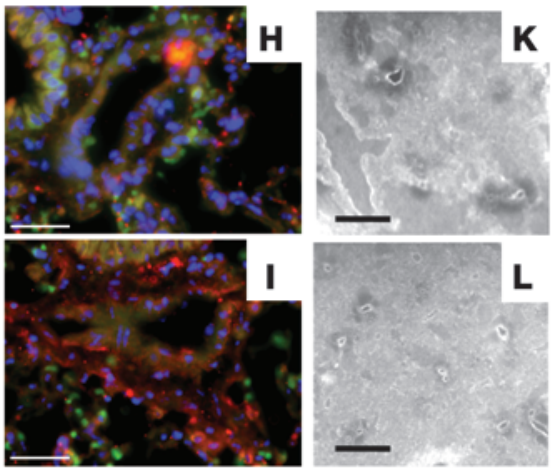

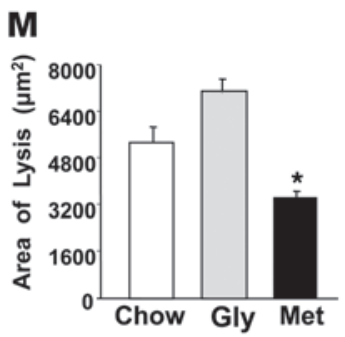

Figure 1

Fibrin accumulation and impaired perivascular fibrinolysis in hyperhomocysteinemic mice. (A-I) For fibrin immunofluorescence, representative sections from renal $(\mathbf{A}-\mathbf{C})$, heart (D-F), and lung $(\mathbf{G}-\mathbf{I})$ tissue from mice on chow $(\mathbf{A}, \mathbf{D}$, and $\mathbf{G})$, Gly $(\mathbf{B}, \mathbf{E}$, and $\mathbf{H})$, or Met (C, F, and I) diets were stained with either rabbit anti-human fibrin(ogen) or nonimmune rabbit lgG (not shown), followed by secondary CY3 (red) and DAPI (blue). Tissue autofluorescence is green. Original magnification, $\times 400$. Scale bars: $100 \mu \mathrm{m}$. (J-L) For casein zymography, 15- $\mu \mathrm{m}$ sections of lung tissue from mice on chow $(\mathbf{J})$, Gly $(\mathbf{K})$, or Met $(\mathbf{L})$ diets were overlaid with a plasminogen-containing casein gel and incubated $\left(21^{\circ} \mathrm{C}, 90\right.$ minutes). Zones of lysis were photographed at 90 minutes under darkfield microscopy. Scale bars: $100 \mu \mathrm{m}$. (M) Perivascular caseinolysis surrounding bronchial microvessels was quantified in photographic images. Lysis zones were calculated for at least 10 vessels per photographic field within representative samples. Values shown are mean areas $\pm \mathrm{SEM}, n=10 .{ }^{*} P<0.001$ versus both Gly and chow diets.

deficiencies (29-32). After establishing the initial rate of blood flow, recording was stopped while $\mathrm{FeCl}_{3}$ was applied for $105 \mathrm{sec}-$ onds to the adventitial surface of the carotid artery. Post-injury blood flow was then recorded over the next 30 minutes. In all 3 groups, initial blood flow was equivalent $(1.08 \pm 0.05,1.11 \pm 0.14$, and $1.02 \pm 0.11 \mathrm{ml} / \mathrm{min}$; mean $\pm \mathrm{SEM}, n=7$, for chow, Gly, and Met diets, respectively). Following vascular injury, however, complete arterial occlusion occurred in 6 of 7 mice on the Met diet but in only 1 of 7 mice on either the chow or Gly diet (Figure 2A). In addition, mean post-injury blood flow in mice on the chow and Gly diets $(106 \% \pm 8 \%$ vs. $88 \% \pm 11 \%$ of baseline, respectively; mean \pm SEM, $n=7$ ) did not differ significantly from the initial rate, while post-injury blood flow in mice on the Met diet was markedly reduced $(50 \% \pm 11 \%$; mean $\pm \mathrm{SEM}, n=7, P<0.001$; Figure $2 \mathrm{C})$. These results suggest that the hyperhomocysteinemic mouse exhibits a prothrombotic defect.

Hyperhomocysteinemia inbibits A2-dependent fibrinolysis. We next examined A2-associated fibrinolytic activity more directly. Immunoblot analysis of reduced gels containing membrane proteins extracted from lung tissue of mice on chow, Gly, or Met diets revealed that the total concentration of $\mathrm{A} 2$ did not differ among the 3 samples (Figure 3A). There was, however, a significant reduction in extractable TPA in tissues from the Met mice versus those from mice fed a chow or Gly diet. When TPA-binding capacity of A2 was tested by ligand blot analysis, we observed equivalent binding of TPA to a $36-\mathrm{kDa}$ protein that comigrated with authentic A2 in samples from mice on chow, Gly, and Met diets. When the same experiment was conducted under non-reducing conditions, however, binding of TPA to the $36-\mathrm{kDa}$ protein was evident in samples from mice fed chow and Gly diets, and in recombinant A2, but not in samples from Met diet-fed mice. These results revealed that, whereas A2 tissue levels are unaffected by hyperhomocysteinemia, the A2 extracted from hyperhomocysteinemic mice appeared to have lost its ability to bind TPA. Interestingly, this capacity was completely restored when the sample was treated with a reducing agent, suggesting that the loss of binding of TPA to A2 in hyperhomocysteinemic mice involved the formation of at least 1 disulfide bond. Similarly, while frozen sections of lung tissue from mice on chow and Gly diets bound biotinylated TPA in an overlay assay, sections from mice on the Met diet showed significantly less binding of TPA (Figure 3B).

We previously demonstrated that $\mathrm{HC}$ can derivatize $\mathrm{A} 2$ in vitro through formation of a disulfide linkage with cysteine 8 , thereby impeding the A2-TPA interaction. To determine whether HC-A2 disulfide conjugates can be found in vivo, we employed rabbit IgG directed against the keyhole limpet hemocyanin-conjugated (KLH-conjugated), homocysteinylated A2 N-terminal peptide (Ac-STVHEILC[hCys]KLSLEGD[C]-[KLH]). This antibody displayed weak specific reactivity with lung tissue from mice on chow or Gly diets but strong reactivity when tissue from Met diet-fed mice was examined (Figure 3B). This polyclonal antibody failed to react with any proteins contained within total lysates from Anxa2 $2^{-/}$endothelial cells (data not shown), indicating its specificity for A2. We concluded that Met tissues, in comparison with Gly or chow tissues, contain significantly higher concentrations of homocysteinylated A2 and bind significantly less TPA.

We then examined the effect of hyperhomocysteinemia on the ability of purified A2 to support TPA-dependent plasminogen activation. Native non-reduced A2 was purified to near homogeneity by calcium precipitation and detergent extraction (Figure 3C). In the absence of added A2 or plasminogen, plasmin generation was inefficient (data not shown). Furthermore, addition of A2 purified from 


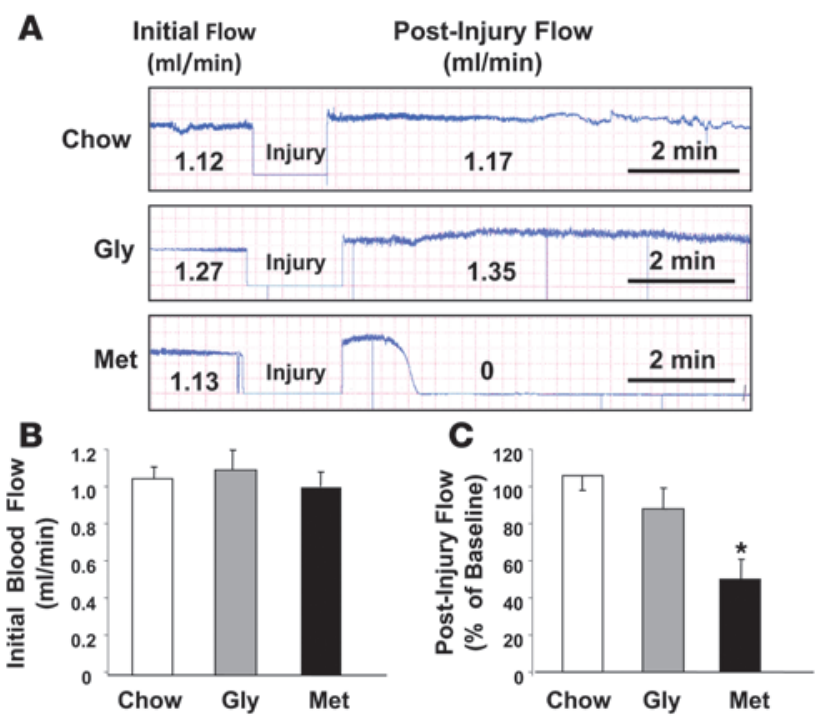

lung tissue of Gly diet-fed mice accelerated plasmin generation by 5- to 6-fold over baseline, while addition of A2 from hyperhomocysteinemic Met mice failed to augment baseline catalytic activity above control levels (Figure 3D). These data establish that in hyperhomocysteinemia the fibrinolytic cofactor activity of A2 is impaired.

$H C$ blocks directed endothelial cell migration. To determine whether HC-induced A2 loss of TPA binding capacity affects directed migration of endothelial cells in vivo, we employed the Matrigel implant assay using both VEGF and bFGF-containing implants. Both agents significantly stimulated vascular invasion in control mice (Figure 4). After 12 days, VEGF-supplemented implants harvested from Gly mice contained $50.2 \pm 6.0$ (mean \pm SEM, $n=7$ ) cells per $0.3 \mathrm{~mm}^{2}$ and numerous erythrocyte-containing neovessels were noted. In contrast, implants from Met mice had $13.5 \pm 1.6$ cells per $0.3 \mathrm{~mm}^{2}$ (mean $\pm \mathrm{SEM}, n=8, P<0.001$ ) and neovessels containing erythrocytes were not seen (Figure $4 \mathrm{~A}$ ). In all sections, about $90 \%$ of invading cells were found to express the endothelial cell marker von Willebrand factor (data not shown). These data suggest that moderate hyperhomocysteinemia impairs endothelial cell invasion of, or survival within, a Matrigel environment.

Similarly, when bFGF-containing Matrigel plugs were supplemented with HC and placed in mice on normal chow, we noted a dose-related diminution of implant cellularity and vascularity compared with plugs treated with bFGF alone (Figure 4B). Based upon manual cell counts and computer-assisted image analysis, the $\mathrm{I}_{50}$ for this effect was approximately $90 \mu \mathrm{M}$ (Figure 4B). In addition, only $\mathrm{HC}$, and not cysteine and methionine, impaired Matrigel invasion (Figure 4C). While HC $(100 \mu \mathrm{M})$ blocked $62.8 \%$ of cellular infiltration seen in the control ( $40.8 \pm 10.1$ versus $104.6 \pm 21.2$ cells/ $0.3 \mathrm{~mm}^{2}$; mean \pm SEM, $n=3, P<0.01$ ), cysteine blocked only $2.3 \%$ $\left(97.7 \pm 18.5\right.$ cells $/ 0.3 \mathrm{~mm}^{2}$; mean $\left.\pm \mathrm{SEM}, n=3, P=\mathrm{NS}\right)$, and methionine enhanced cellularity by $30.2 \%$ (142.7 \pm 47.5 cells $/ 0.3 \mathrm{~mm}^{2}$; mean \pm SEM, $n=3, P=$ NS; Figure 4C). Similar values were obtained by computer-assisted image analysis (HC $64.7 \% \pm 5.9 \%$ inhibition, mean \pm SEM, $n=18$; cysteine $21.6 \% \pm 7.8 \%$ inhibition, mean \pm SEM, $n=6$; and methionine $35.3 \% \pm 13.7 \%$ enhancement, mean \pm SEM, $n=5)$. Therefore, we determined that among sulfur-containing amino acids, $\mathrm{HC}$ has a selective ability to block endothelial cell invasion of, or survival within, bFGF-containing implanted matrix.

\section{Figure 2}

Carotid artery thrombolysis. Carotid arteries were injured by application of $\mathrm{FeCl}_{3}$ to the adventitial surface, and blood flow was monitored before and after injury using a Doppler flow probe. (A) Representative carotid blood flow tracings for mice on chow, Gly, and Met diets before and after arterial injury. Values for mean initial and post-injury flow are shown for representative mice. (B) Mean initial blood flow rates for mice on chow, Gly, and Met diets (mean \pm SEM, $n=7$ ). (C) Mean post-injury blood flow, calculated as the area under the flow curve, for mice on chow, Gly, and Met diets (mean \pm SEM, $n=7$ ). ${ }^{*} P<0.001$ versus chow or Gly diet.

We next assessed the effect of homocysteine on endothelial cell survival, proliferation, or non-directed motility. Incubation of human dermal microvascular endothelial cells (HDMECs) with HC $(0,10$, and $100 \mu \mathrm{M} ; 24$ hours) had no significant effect on cell survival, as judged by the ability to exclude Trypan blue $(10.9 \% \pm 3.4 \%$, $11.4 \% \pm 5.3 \%$, and $17.9 \% \pm 2.7 \%$, mean $\pm \mathrm{SD}, n=3, P=\mathrm{NS}$ ). In addition, numbers of proliferating endothelial cells recovered 72 hours after plating at low density in $\mathrm{HC}$-containing medium $(0,10$, or $100 \mu \mathrm{M})$ did not differ significantly $(179,000 \pm 62,200,167,500 \pm 23,300$, and $162,500 \pm 14,000$, respectively, mean $\pm \mathrm{SD}, n=3, P=\mathrm{NS}$ ). Similarly, there was no difference in random cell motility through uncoated porous membranes between untreated and HC-treated $(10$ or $100 \mu \mathrm{M})$ cells $(3,658 \pm 1,033$ cells; $2,773 \pm 797$ cells; and $2,626 \pm 767$ cells, respectively, mean \pm SEM, $n=5, P=\mathrm{NS})$. These data suggest that basal endothelial cell survival, proliferation, and motility were not significantly altered by HC.

To test the potential effect of $\mathrm{HC}$ on microvascular endothelial cell matrix invasion, HDMECs were pre-incubated for 24 hours with HC $(10-1,000 \mu \mathrm{M})$ and plated on porous membranes placed atop modified Boyden chambers containing VEGF-A-supplemented medium. In the untreated control samples, cells that migrated through the filter represented $28.6 \pm 6.5,24.0 \pm 3.8$, and $23.4 \pm 4.6$ cells per $0.3 \mathrm{~mm}^{2}$ (mean \pm SEM, $n=3$ ) of those plated on filters coated with gelatin, Matrigel, and fibrin, respectively $\left(\sim 20\right.$ cells per $\left.0.3 \mathrm{~mm}^{2}\right)$. Upon pretreatment of cells with HC, however, we observed a dose-related diminution in the number of cells that penetrated filters coated with each of the 3 artificial matrices (Figure 5A). When cells were co-incubated, rather than pre-incubated, with HC, we observed no effect upon their invasive capability. Treatment with HC inhibited endothelial cell invasion through Matrigel, gelatin, and fibrin ( $\mathrm{I}_{50}$ values 5,8 , and $150 \mu \mathrm{M}$ HC, respectively).

We next compared the effect of $\mathrm{HC}$ on directed endothelial cell migration with the effect of other sulfur-containing amino acids. While HC $(100 \mu \mathrm{M})$ pretreatment of endothelial cells effectively blocked VEGF-induced migration through gelatin (21.8 \pm 6.9 vs. $39.9 \pm 4.4$ cells per $0.3 \mathrm{~mm}^{2}$, mean $\left.\pm \mathrm{SEM}, n=3, P<0.05\right)$, Matrigel $\left(6.5 \pm 0.4\right.$ vs. $21.9 \pm 4.5$ cells per $0.3 \mathrm{~mm}^{2}$, mean $\pm \mathrm{SEM}, n=3$, $P<0.01)$, and fibrin $\left(8.5 \pm 0.8\right.$ vs. $23.6 \pm 1.4$ cells per $0.3 \mathrm{~mm}^{2}$, mean \pm SEM, $P<0.001$ ) by $44.5 \%, 70.3 \%$, and $64.0 \%$, respectively, cysteine, methionine (Figure 5B), and homocystine (data not shown) had no effect at the same concentration. Thus, HC specifically impaired directed migration of HDMECs in response to VEGF-A in vitro, the most statistically significant effect having been observed in the setting of a fibrin barrier.

Hyperhomocysteinemia inhibits corneal neoangiogenesis. To further evaluate the in vivo neoangiogenic response in the setting of hyperhomocysteinemia, we placed bFGF-containing pellets with- 
A

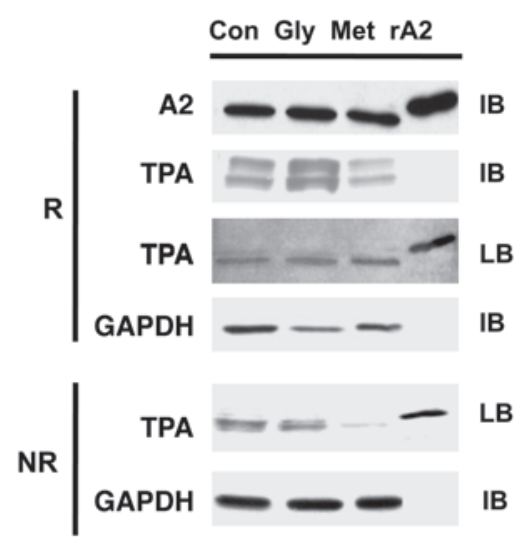

C

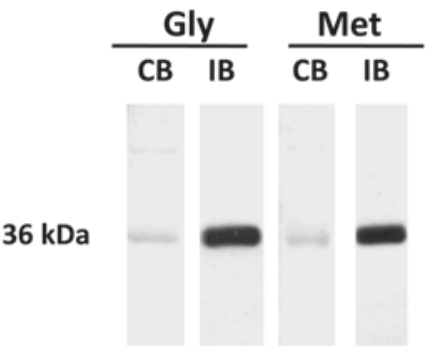

B TPA Overlay
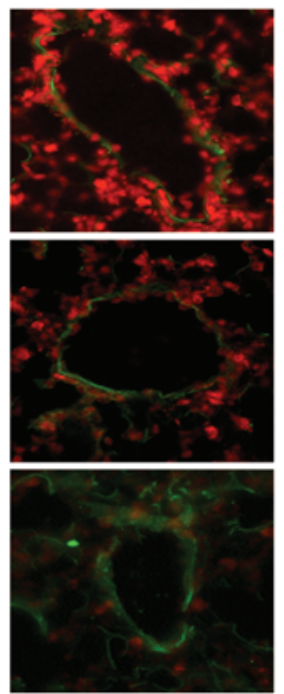

Chow

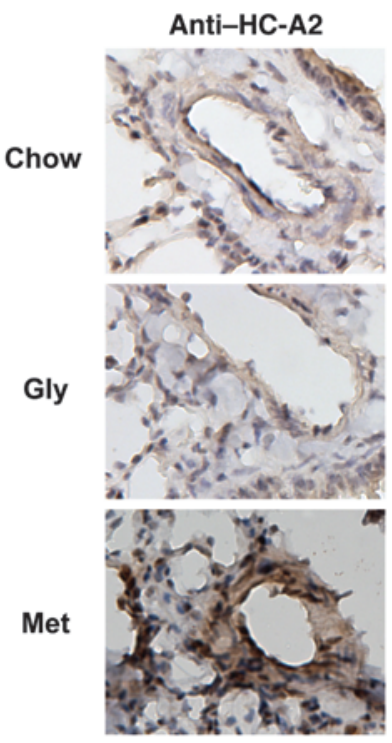

D

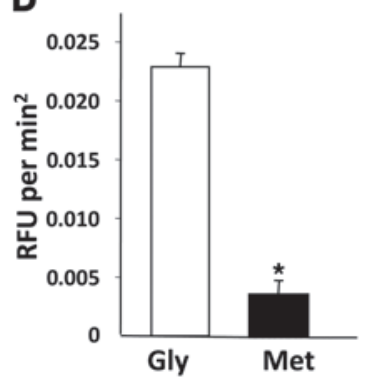

Figure 3

Effect of HC on A2 binding of TPA and plasmin generation. (A) Lung membrane proteins from mice maintained on chow, Gly, or Met diets and rA2 $(1 \mu \mathrm{g})$ were immunoblotted with rabbit anti-mouse TPA or mouse anti-A2 IgG. For ligand blotting (LB), proteins resolved under reducing (R) or non-reducing (NR) conditions were incubated with human TPA and then probed with rabbit anti-mouse TPA. GAPDH served as a loading control. (B) Left: Cryosections from mice on chow, Gly, or Met diets were incubated with biotinylated TPA and stained as described in Methods. Right: Paraffin-embedded lung sections were stained with rabbit anti-HC-A2 tail peptide IgG as described in Methods. Original magnification, $\times 200$. (C) Purification of native A2. Reduced Coomassie blue-stained (CB) SDS-PAGE and immunoblot analysis with monoclonal anti-A2 of native A2 purified from lung tissue of mice on Gly and Met diets. Samples were run on noncontiguous lanes of the same gel. (D) TPA-dependent plasmin generation in the presence of A2 purified from lung tissue. Initial rates of hydrolysis of a fluorogenic plasmin substrate were calculated as described in Methods. RFU, relative fluorescence units. ${ }^{*} P<0.001$ versus Gly.

in the normally avascular cornea (33). In Met diet-fed mice, the area of neovascular response (angiogenic index) was 6-fold less $\left(0.3 \pm 0.2\right.$ vs. $1.8 \pm 0.4 \mathrm{~mm}^{2}$, mean $\left.\pm \operatorname{SEM}, n=14\right)$ (data not shown) than in Gly diet-fed mice. Similarly, maximum neovessel length was reduced in Met mice $(0.4 \pm 0.1$ vs. $1.1 \pm 0.2 \mathrm{~mm}$, mean \pm SEM, $n=14$ ), as was the number of vessels greater than $0.5 \mathrm{~mm}$ in length $(0.7 \pm 0.3$ vs. $2.6 \pm 0.6$, mean \pm SEM, $n=14)$ (data not shown). These data indicate that bFGF-driven neoangiogenesis was inhibited in diet-induced hyperhomocysteinemia.

Next we asked whether the defect in corneal neoangiogenesis could be repaired upon introduction of fresh recombinant A2. In mice on chow or Gly diets, we found no significant difference in neovascular area when mice were treated with supplemental A2 $(1 \mathrm{mg} / \mathrm{kg}$ i.v. once per day for 5 days) versus BSA $\left(2.1 \pm 0.3\right.$ and $2.5 \pm 0.6 \mathrm{~mm}^{2}$ vs. $2.4 \pm 0.01$ and $2.2 \pm 0.4 \mathrm{~mm}^{2}$, mean \pm SEM, $n=3$ ) (Figure 6, $A$ and B). On the other hand, angiogenesis in the Met diet-fed mice remained severely depressed following BSA treatment $\left(0.6 \pm 0.2 \mathrm{~mm}^{2}\right.$, mean $\left.\pm \mathrm{SEM}, n=3, P<0.01\right)$ but improved dramatically following treatment with recombinant His-tagged A2 $\left(1.9 \pm 0.1 \mathrm{~mm}^{2}\right.$, mean \pm SEM, $n=3$ ) (Figure $6, \mathrm{~A}$ and $\mathrm{B}$ ). This effect was not due to contamination of the recombinant His-tagged A2 (rA2) preparation with bacterial products because material prepared in a parallel fashion from mock-transfected $E$. coli had no effect on corneal angiogenesis (data not shown). This result indicated that the homocysteinemia-associated defect in neoangiogenesis could be completely corrected with recombinant A2.

Although Anxa2 $2^{-/-}$mice showed reduced neovascular area compared with $A n x a 2^{+/+}$mice, neoangiogenesis was not further depressed when $A n x a 2^{-/-}$mice were placed on the Met diet (Figure $6 \mathrm{C})$, suggesting that $\mathrm{HC}$ may impair angiogenesis through interference with an A2-related pathway. Confocal microscopy, moreover, revealed colocalization of anti-PentaHis immunoreactivity with immunostaining for the endothelial cell marker MECA-32 in corneal tissue from mice treated with rA2 (Figure 6D). Thus, the angiogenic defect associated with hyperhomocysteinemia can be corrected by supplementation with exogenous rA2. 
A
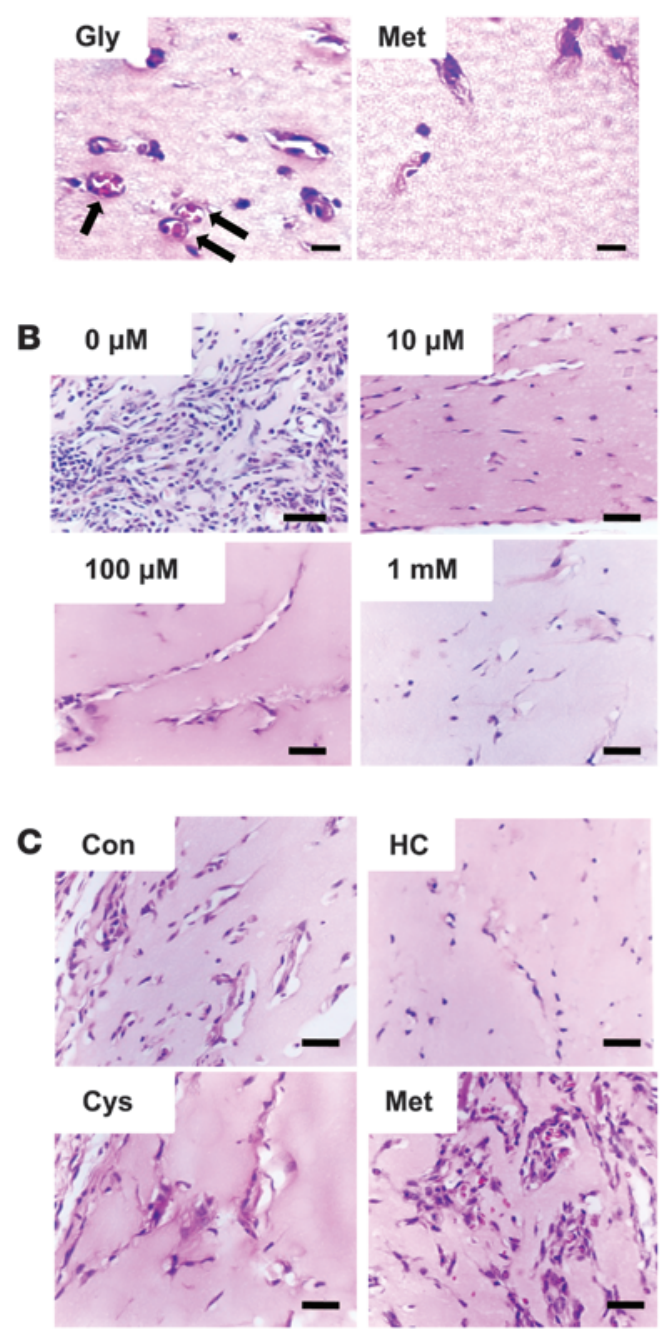
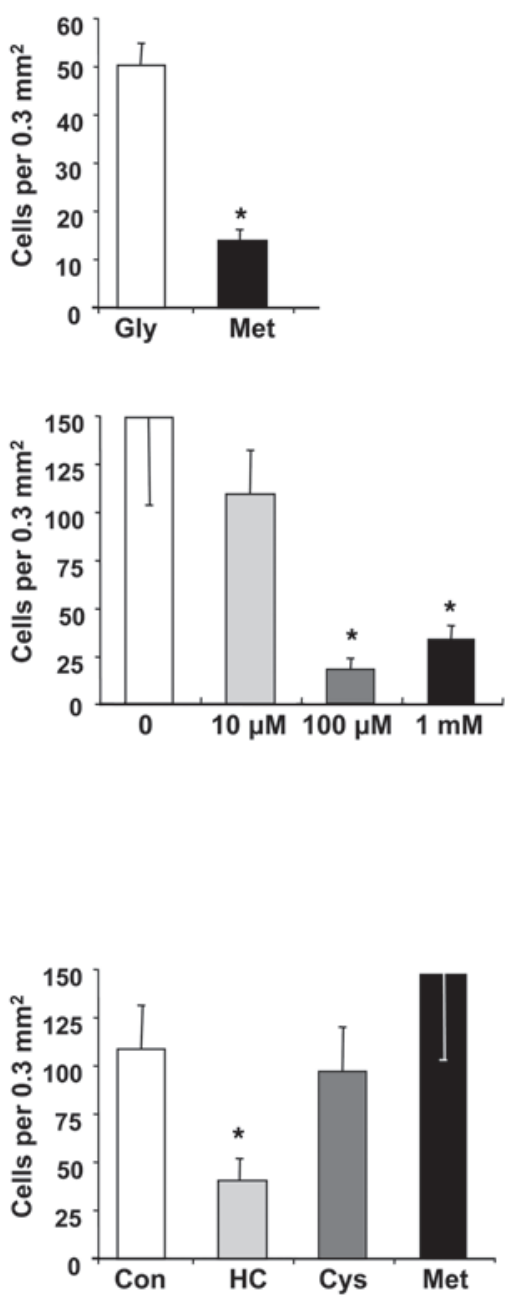

\section{Figure 4}

Effect of $\mathrm{HC}$ on endothelial cell invasion of Matrigel implants. (A) Left: Sections from Matrigel implants containing VEGF-A (100 ng/ml) harvested from mice on Gly and Met diets. Arrows indicate erythrocyte-containing neovessels. Right: Matrigel plug cellularity, assessed as described in Methods. Shown are mean \pm SEM for 8 separate plugs, 10 fields per plug. Scale bars: $20 \mu \mathrm{m}$. (B) Left: Sections from Matri-

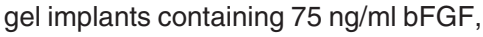
$100 \mu \mathrm{g} / \mathrm{ml}$ heparin, and the indicated concentrations of DL-HC, harvested from mice maintained on a normal chow diet. Right: Matrigel plug cellularity. Shown are mean \pm SEM for 3 separate plugs, 10 fields per plug. Scale bars: $50 \mu \mathrm{m}$. (C) Left: Sections from Matrigel implants containing $75 \mathrm{ng} / \mathrm{ml}$ bFGF and $100 \mu \mathrm{g} / \mathrm{ml}$ heparin with or without $100 \mu \mathrm{M}$ DL-HC, L-cysteine, or $\mathrm{L}$-methionine, harvested from mice on a normal chow diet. Right: Matrigel plug cellularity. Shown are mean \pm SEM for 3 separate plugs, 10 fields per plug. Scale bars: $50 \mu \mathrm{m}$. All sections were stained with hematoxylin and eosin. ${ }^{*} P<0.01$ versus control.
Finally, we asked whether fibrin might constitute a barrier to neovessel growth in Met diet-fed mice (Figure 6E). While neovessels within the corneas of rA2-treated mice were essentially devoid of immunohistochemically detectable fibrin, those within corneas of BSA-treated mice showed significant deposition, with fibrin strands partially obliterating the vascular lumen. Results of these experiments strongly suggest that excessive fibrin deposition represents a significant barrier to neoangiogenesis in the hyperhomocysteinemic mouse cornea.

\section{Discussion}

In 1969, McCully reported widespread atherosclerosis-like arterial disease at postmortem in an infant with hyperhomocysteinemia due to an inborn error of cobalamin metabolism (34). Since then, numerous studies, including recent meta-analyses, have confirmed an association between elevated circulating HC levels and macrovascular atherothrombotic disease, including coronary artery occlusion, stroke, and venous thromboembolism (35). Although there is now strong evidence that HC-lowering therapies reduce the incidence of major vascular events in patients with severe hyperhomocysteinemia, it remains unresolved as to whether treatment of mildly elevated HC lowers the risk of vascular disease (36-38).
Against this backdrop, there is renewed interest in $\mathrm{HC}$ as an etiologic agent in microvasculopathies. Hyperhomocysteinemia has emerged as an independent risk factor for cerebral small vessel disease, which may lead to lacunar infarction and accounts for about $25 \%$ of ischemic strokes $(19,39-42)$. In older individuals, several large cross-sectional studies have linked hyperhomocysteinemia with depression and with small vessel disease-related dementias, including Alzheimer disease (43-45). Hyperhomocysteinemia may also be a new risk factor for proliferative retinopathy and nephropathy in type 2 diabetes (46) as well as chronic lower extremity ulceration in patients with or without diabetes (47). While these associations could reflect impairment of microvascular thromboresistance or inhibition of microvascular remodeling, clear mechanistic insights have been lacking $(48,49)$.

In the current study, we report for the first time that moderate diet-induced hyperhomocysteinemia (an increase from 11 to $70 \mu \mathrm{M}$ ) in the mouse is associated with impairment of fibrin homeostasis and reduced angiogenesis. We observed fibrin accumulation and reduced perivascular fibrinolytic activity within microvessels of several tissues such as kidney, heart, and lung in hyperhomocysteinemic mice (Figure 1). Similarly, clot lysis following arterial injury was dramatically inhibited in hyperhomocysteinemic 
A

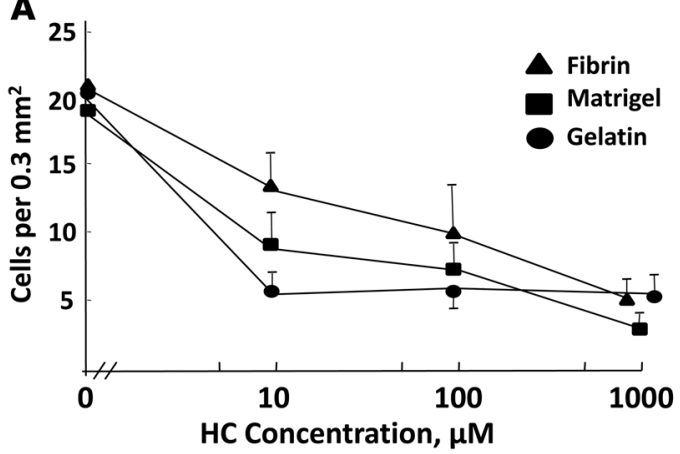

B

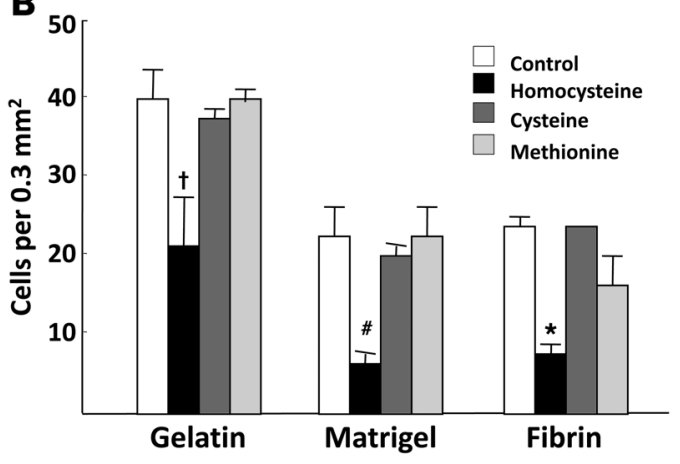

mice, further suggesting a significant defect in vascular fibrinolysis (Figure 2). Subsequent studies revealed dysfunction of A2, the major profibrinolytic receptor on resting endothelial cells, impaired endothelial cell migration, and blocked angiogenesis (Figures 3-6). Our data suggest, for what we believe is the first time, that vascular fibrinolysis and angiogenesis are closely aligned through regulation of fibrin homeostasis.

While elevated plasma HC concentrations have been associated with mild impairment of plasma fibrinolysis in humans, the clinical significance of these findings remains unknown. Mild elevations in plasma HC (15.75-16.80 vs. $12.35 \mu \mathrm{M})$ appear to correlate with somewhat prolonged plasma clot lysis times (8.7-8.8 vs. 7.9 minutes) (50). In patients with venous thromboembolism, moderate hyperhomocysteinemia $(24.2 \mu \mathrm{M})$ was associated with elevations of thrombin-activatable fibrinolysis inhibitor (13\%), and prolonged plasma clot lysis times (12\%) (51). In rabbits, injected HC may induce a dysfibrinogenemia, leading to abnormal plasma clot structure ex vivo and resistance to fibrinolysis (52). Although these observations are of interest, the molecular mechanisms that underlie them remain obscure.

Vascular fibrinolysis was first observed by Todd in 1964 (53), who determined that when fibrin gels were applied directly to fresh tissue sections, fibrinolysis was specifically localized to blood vessels and required the integrity of the endothelium. Subsequently, TPA was identified as a secretory product of endothelial cells within specific vessel types in defined anatomic locations $(3,54,55)$. Urokinase and its receptor, on the other hand, appear to be localized to either renal or cytokine-activated endothelial cells $(56,57)$. In contrast, the A2 complex has been identified as a major receptor for both TPA and its substrate, plasminogen, on resting and activated endothelial cells $(7,10)$. The A2-null mouse, moreover, displays normal plasma clot lysis but severe defects in endothelial cell-associated fibrinolytic activity and postnatal angiogenesis (11).

\section{Figure 5}

Effect of HC on directed migration of HDMECs. (A) Dose response. Confluent HDMECs were preincubated for 24 hours with the indicated concentrations of DL-HC, then plated (25,000 cells per filter) onto filters pre-coated with fibrin, Matrigel, or gelatin and positioned over wells containing complete medium supplemented with VEGF-A. After 12 hours, cells adherent to the upper surface of the filter were removed, and cells on the under surface were fixed and stained with hematoxylin. (B) Specificity. HDMECs were pretreated (24 hours) with the indicated sulfur-containing amino acids $(100 \mu \mathrm{M})$, then plated at 50,000 cells per filter coated as described in A. In each experiment, cell migration was assessed in 10 fields from each of 3 duplicate filters. Data are mean \pm SEM, $n=3$ filters. ${ }^{\dagger} P<0.05,{ }^{\#} P<0.01,{ }^{*} P<0.001$ versus control.

The present study shows that, while levels of total lung A2 did not differ between normo- and hyperhomocysteinemic mice, the TPAbinding ability of A2 from hyperhomocysteinemic lungs was dramatically diminished (Figure 3). This loss of binding capacity was completely restored upon reduction of A2 thiols. Lung tissue from Met diet-fed mice, furthermore, showed impaired TPA binding, leading to the conclusion that modification of A2 through a HC-mediated oxidative mechanism blocks its ability to interact with TPA. In further support of this postulate, we found that IgG, directed at an HC-derivatized N-terminal A2 peptide, bound avidly to vessels and perivascular lung tissue from Met diet-fed mice, but weakly to vessels in lungs of chow diet-fed or Gly diet-fed mice. Finally, A2 purified from hyperhomocysteinemic mice failed to significantly stimulate TPA-dependent plasminogen activation in vitro. Together these data indicate that direct $\mathrm{HC}$ derivatization of A2 impairs TPA binding and prevents plasmin generation at the endothelial cell surface.

Our second major finding was that diet-induced hyperhomocysteinemia is associated with impaired angiogenesis in the mouse. Matrigel implants were far less extensively vascularized in hyperhomocysteinemic mice than in normohomocysteinemic mice (Figure 4). Matrigel supplemented directly with HC showed impaired neoangiogenesis, thus ruling out a non-HC-related anti-angiogenic effect of the Met diet. HC also blocked directed endothelial cell migration in a specific and dose-related fashion in vitro (Figure 5). These data indicate that HC inhibits endothelial cell migration by blocking the cell's ability to generate cell surface plasmin and by diminishing its activation of downstream proteases such as MMP-3 and -13 (11).

To date, there are few studies that link fibrin to dysangiogenesis. In our study, hyperhomocysteinemic mice displayed a deficiency in angiogenesis, which could be completely and specifically reversed upon infusion of recombinant A2 (Figure 6, A and B). While the hyperhomocysteinemic diet specifically reduced corneal angiogenesis in $A n x a 2^{+/+}$mice, no further reduction, beyond that due to A2 deficiency itself, was observed when $A n \times a 2^{-/-}$mice were placed on the Met diet, suggesting that $\mathrm{HC}$ targets the $\mathrm{A} 2$ pathway (Figure $6 \mathrm{C})$. We noted further that infused rA2 localized to corneal neovascular endothelial cells in hyperhomocysteinemic mice (Figure 6D) and prevented fibrin accumulation and microvascular occlusion (Figure 6E). Taken together, these data reveal that homocysteine derivatizes A2 in vivo, leading to blockade of endothelial cell surface plasmin generation, formation of a fibrin barrier, loss of endothelial cell migratory ability, and angiogenic failure.

Our findings have several significant implications. First, although fibrin has been suggested to play a potentiating role in angiogenesis, based largely upon in vitro observations (58), 
A

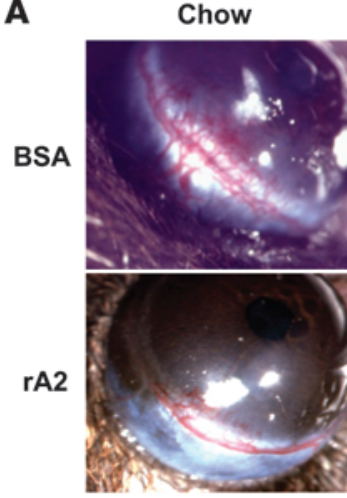

B

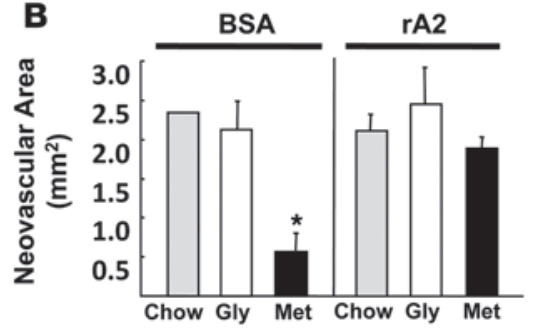

Gly

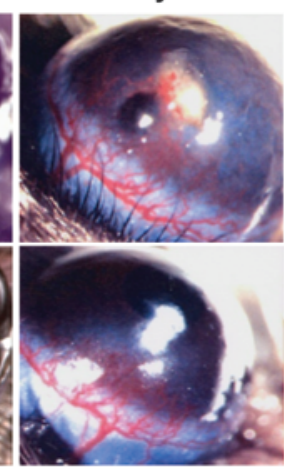

C

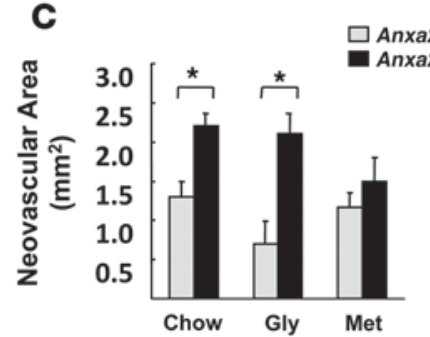

Met

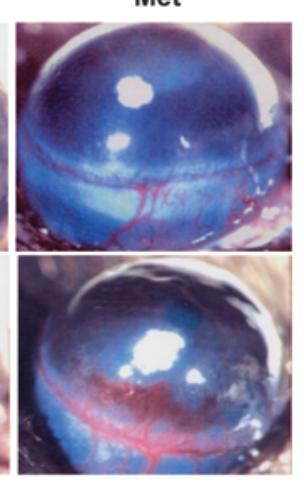

Chow

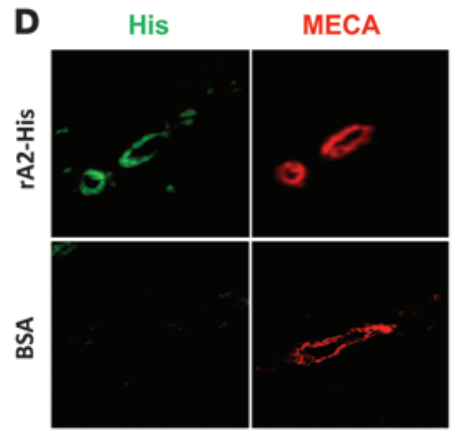

Merge

E

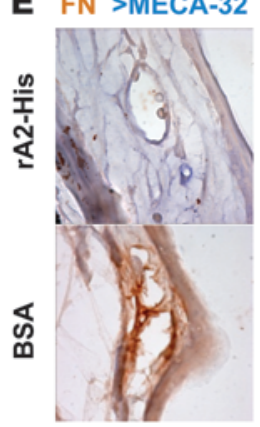

\section{Figure 6}

Effect of hyperhomocysteinemia on corneal pocket neoangiogenesis. (A) Corneal angiogenesis in mice maintained on chow, Gly, or Met diets. Following implantation of bFGFcontaining pellets, mice received 5 daily tail vein injections of either BSA or rA2. Shown are representative photographs of corneal neovessels. (B) Neovascular area shown as mean values \pm SEM, $n=3$. ${ }^{*} P<0.01$ versus all other groups. (C) Neovascular area from corneal pocket assays in Anxa2 ${ }^{+/+}$and Anxa2 $2^{-/-}$ mice on chow, Gly, or Met diets. Shown are mean values \pm SEM, $n=9$. ${ }^{\star} P<0.001$. (D) Confocal immunofluorescence analysis of corneal neovessels in mice maintained on the Met diet and treated with i.v. BSA or rA2 as described in A. On day 5, corneal tissue was harvested and stained with anti-MECA-32 (red), Penta-His IgG (green), and DAPI (blue). Original magnification, $\times 75$. (E) Sections prepared as described in $\mathbf{D}$ were stained with rabbit anti-human fibrin(ogen) IgG (brown) and rat MECA-32 IgG (blue). Original magnification, $\times 800$. we demonstrate that fibrin, the provisional matrix that forms in response to vascular injury, may act as a physical barrier to directed endothelial cell migration. Second, while hyperhomocysteinemia is strongly associated with atherothrombotic vascular disease in humans, there is, to our knowledge, no prior report of its association with dysangiogenesis in non-ischemic tissues. Third, our findings suggest that mice with diet-induced elevations of HC closely phenocopy the A2-null mouse, suggesting that $\mathrm{HC}$ and $\mathrm{A} 2$ belong to a common pathway relevant to fibrin homeostasis and angiogenesis. Taken together, the data provide a mechanistic explanation for vascular dysfunction in the setting of hyperhomocysteinemia, particularly at the level of the microvasculature. Direct blockade of A2 profibrinolytic function by $\mathrm{HC}$ might underlie the pathogenesis of small vessel disease associated with dementia, depression, chronic wounds, and diabetes.

\section{Methods}

Reagents. Cell culture media, supplements, and sera were purchased from Life Technologies. Male C57BL/6 mice (6 weeks of age) were purchased from The Jackson Laboratory. Recombinant human TPA was provided by Genentech. Glu-plasminogen was purchased from American Diagnostica. The fluorogenic plasmin substrate AFC-81 (D-Val-Leu-Lys-7-amino-4trifluoromethylcoumarin) was obtained from Enzyme Systems Products. Gelatin powder was purchased from J.T. Baker Chemical, Matrigel from
Collaborative Biomedical Products (Becton Dickinson), agarose from Boehringer Mannheim $\mathrm{GmbH}$, and 95\% clottable bovine fibrinogen from Miles Scientific. Bovine thrombin, DL-HC, L-cysteine, and L-methionine were obtained from Sigma-Aldrich. Recombinant VEGF was purchased from R\&D Systems, and recombinant FGF from Research Diagnostics.

Diet-induced hyperhomocysteinemia in mice. For an 8- to 10-week period, 6-week-old C57BL/6 mice were fed standard chow (catalog 20-5053, PicoLab; LabDiet), a Met diet (catalog TD 98399; Harlan Teklad), or a Gly diet (catalog TD 98400) (59). Met and Gly diets contained the following components per kilogram of chow: $60 \mathrm{~g}$ soybean oil, $195 \mathrm{~g}$ casein, $20 \mathrm{~g}$ methionine or glycine, $325 \mathrm{~g}$ sucrose, $301 \mathrm{~g}$ corn starch, $50 \mathrm{~g}$ cellulose, $35 \mathrm{~g}$ mineral mix (catalog TD 94046) to provide $4 \mathrm{~g} \mathrm{CaHPO}_{4}$, and $10 \mathrm{~g}$ vitamin mix (cata$\log$ TD 40060). The methionine and B vitamin content of all diets used is described in Table 2. Met and Gly diets provided approximately $7.4 \mu \mathrm{g}$ of folic acid, while standard chow provided about $11.2 \mu \mathrm{g}$ of folic acid per day, assuming daily consumption of about $3.75 \mathrm{~g}$ chow. All animals had ad libitum access to food and water. Plasma HC levels were determined using the Homocysteine Microtiter Plate Assay (American Laboratory Products) according to the manufacturer's instructions. Animal work in all studies was approved by the Institutional Animal Care and Use Committee of Weill Cornell Medical College.

Hematologic parameters. Hematocrit values, platelet counts, and white blood cell counts were measured in a Cell Dyn 3700 analyzer (Abbott Diagnostics) in the Laboratory of Comparative Pathology of Weill Cornell Med- 


\section{Table 2}

Characteristics of chow, Gly, and Met diets

\begin{tabular}{lccc} 
Dietary constituent & Chow & Gly & Met \\
Methionine $(\mathrm{g} / \mathrm{kg})$ & 4.2 & 4.3 & 24.3 \\
Folate $(\mathrm{mg} / \mathrm{kg})$ & 3.0 & 1.98 & 1.98 \\
$\mathrm{~B}_{12}(\mu \mathrm{g} / \mathrm{kg})$ & 51 & 29.7 & 29.7 \\
$\mathrm{~B}_{6}(\mathrm{mg} / \mathrm{kg})$ & 9.6 & 22.0 & 22.0 \\
Choline $(\mathrm{g} / \mathrm{kg})$ & 2.0 & 3.5 & 3.5 \\
\hline
\end{tabular}

ical College. Platelet aggregometry was carried out as previously described (60). Fibrinogen was estimated by IDEXX Veterinary Services. Plasma clotting time and half-maximal clot lysis time were measured as previously reported $(11,61)$. Plasmin-antiplasmin complex and D-dimer assays were performed using the Imuclone ELISA kits (American Diagnostica).

Immunohistochemistry and immunofluorescence staining. Mice were anesthetized with Avertin and then perfused with PBS containing calcium and magnesium (PBS C/M). Kidney, heart, and lung tissues were immersionfixed in $4 \%$ PFA for 18 hours. For cryostat sections, tissues were incubated in $30 \%$ sucrose in PBS C/M (18 hours at $\left.4^{\circ} \mathrm{C}\right)$, embedded in OCT $/ 30 \%$ sucrose $(2: 1, \mathrm{vol} / \mathrm{vol})$, and sectioned at $8-10 \mu \mathrm{m}$. Tissues were infiltrated with paraffin using a VIP tissue processor and sectioned at 5-6 $\mu \mathrm{m}$.

For fibrin immunofluorescence staining, heart and kidney cryosections were treated with $1 \%$ sodium borohydride in PBS C/M (5 minutes), and blocked with $5 \%$ BSA, $10 \%$ donkey serum, and $1 \%$ mouse serum in PBS $\mathrm{C} / \mathrm{M}$ (20 minutes). Sections were incubated with rabbit anti-fibrin(ogen) (Dako; $1: 3,000 ; 21^{\circ} \mathrm{C}, 90$ minutes), followed by donkey anti-rabbit CY3 (Jackson ImmunoResearch Laboratories; $1: 250 ; 21^{\circ} \mathrm{C}, 30$ minutes) and DAPI (Invitrogen; $1: 10,000 ; 21^{\circ} \mathrm{C}, 5$ minutes). Lung sections were deparaffinized, subjected to antigen retrieval, treated with $1 \%$ sodium borohydride in PBS C/M (5 minutes), blocked for endogenous avidin and biotin (15 minutes), and blocked with $5 \%$ BSA, $10 \%$ goat serum, and $1 \%$ mouse serum in PBS C/M (20 minutes). The sections were incubated with rabbit anti-fibrin(ogen) (Dako; $1: 1,000,21^{\circ} \mathrm{C}, 90$ minutes), followed by biotinylated goat anti-rabbit (Vector Laboratories; $1: 250,21^{\circ} \mathrm{C}, 30$ minutes), Streptavidin 568 (Invitrogen; 1:300), and finally DAPI.

For tissue overlay studies, lungs were inflated with $50 \% \mathrm{vol} / \mathrm{vol}$ TissueTek OCT in 10\% sucrose in PBS C/M and frozen immediately in OCT $/ 30 \%$ sucrose $(2: 1, \mathrm{vol} / \mathrm{vol})$ in PBS C/M. Sections $(12 \mu \mathrm{m})$ were maintained at $-20^{\circ} \mathrm{C}$ and thawed for 30 seconds immediately prior to use. All subsequent steps were carried out at $4^{\circ} \mathrm{C}$. The sections were rinsed with cold PBS C/M, treated with $50 \mathrm{mM}$ glycine- $\mathrm{HCl}$ containing $100 \mathrm{mM} \mathrm{NaCl}$ (pH 3; 10 minutes, $4^{\circ} \mathrm{C}$ ), blocked for endogenous avidin and biotin (15 minutes each), and blocked with $1 \%$ BSA (20 minutes). Biotinylated TPA $(220 \mathrm{ng} / \mathrm{ml}$; Innovative Research Inc.) in $1 \% \mathrm{BSA} / \mathrm{PBS} \mathrm{C} / \mathrm{M}$ was applied overnight. The sections were washed and then incubated with Alexa 594-conjugated streptavidin (Invitrogen; $1: 200,4^{\circ} \mathrm{C}, 1$ hour), followed by DAPI.

For staining of $\mathrm{HC}$-derivatized $\mathrm{A} 2$, peptides representing the putative homocysteinylated and unmodified versions of A2 residues 2-16 (Ac-STV HEILC[hCys]KLSLEGD[C]; New England Peptide) were conjugated to KLH and used to immunize rabbits. IgG was purified from antisera by protein $\mathrm{G}$ affinity and evaluated by direct ELISA against both modified and unmodified peptides. For staining of lung tissue, deparaffinized sections were subjected to antigen retrieval, treated with $3 \% \mathrm{H}_{2} \mathrm{O}_{2}$ in methanol (10 minutes), blocked with $2 \% \mathrm{BSA} / 0.1 \%$ Triton $\mathrm{X}-100$ in PBS C/M (20 minutes), incubated with anti-peptide IgG $\left(1: 100,18\right.$ hours, $\left.4^{\circ} \mathrm{C}\right)$, followed by biotinylated goat anti-rabbit (1:250 in 2\% BSA, 30 minutes; Vector), and developed with the Vectastain $\mathrm{ABC}$ Elite (30 minutes) using DAB substrate.
For staining of corneal tissues, $6-\mu \mathrm{m}$ paraffin-embedded sections were blocked with avidin and biotin reagents (Vector), followed by $10 \%$ normal goat serum $/ 3 \% \mathrm{BSA}\left(30\right.$ minutes, $21^{\circ} \mathrm{C}$ ). For endothelial cell staining, sections were incubated with biotin-conjugated rat anti-mouse MECA-32 IgG $\left(1: 50,21^{\circ} \mathrm{C}, 1\right.$ hour $)$ in a humidified chamber, followed by streptavidinconjugated Alexa Fluor 594 (1:200, $21^{\circ} \mathrm{C}, 30$ minutes; Invitrogen). For rA2 staining, sections were incubated with Alexa Fluor 488-conjugated PentaHis monoclonal antibody (Qiagen; $1: 20 ; 4^{\circ} \mathrm{C}, 18$ hours). Finally, all sections were stained with DAPI. Fluorescence images were acquired using a Zeiss LSM 510 confocal system (Carl Zeiss). For fibrin staining, sections were incubated with rabbit anti-human fibrin(ogen) IgG (Dako; 1:1,000, 90 minutes, $21^{\circ} \mathrm{C}$ ) followed by HRP-conjugated goat anti-rabbit IgG (ImmPress, Vector; $1: 135,30$ minutes, $21^{\circ} \mathrm{C}$ ) and Vector Nova Red substrate. Corneal neovessels were costained with rat panendothelial cell monoclonal IgG (MECA-32; 1:50, 18 hours, $4^{\circ} \mathrm{C}$; BD Biosciences - Pharmingen), followed by biotinylated rabbit anti-rat IgG $\left(1: 135,30\right.$ minutes, $\left.21^{\circ} \mathrm{C}\right)$, avidin-conjugated $\mathrm{ABC}$ alkaline phosphatase, and Vector Blue substrate (Vector).

Casein zymography. Mice were euthanized by $\mathrm{CO}_{2}$ inhalation, followed by cervical dislocation. Harvested lung tissue was washed with ice-cold PBS, embedded in OCT, snap frozen in liquid $\mathrm{N}_{2}$, and stored at $-80^{\circ} \mathrm{C}$. Frozen sections $(15 \mu \mathrm{m})$ were overlaid with $120 \mu \mathrm{l}$ of $1 \%$ low-melting-point agarose in $10 \mathrm{mM}$ Tris ( $\mathrm{pH} 7.5$ ) containing plasminogen (American Diagnostica; $25 \mu \mathrm{g} / \mathrm{ml}$ ) and $2.5 \%$ (wt/vol) boiled nonfat dry milk (Carnation), topped with a coverslip, and incubated in a humidified chamber $\left(21^{\circ} \mathrm{C}, 90 \mathrm{~min}\right.$ utes). Slides were evaluated under dark field illumination using a Zeiss Axioplan-IE microscope (Carl Zeiss) (3). Perivascular fibrinolysis was quantified as the area of the roughly circular zones of lysis surrounding bronchial vessels between 10 and $50 \mu \mathrm{m}$ in diameter. For each zone, 2 perpendicular diameters were averaged, and this value was used to compute total lysis area surrounding each vessel according to the formula $\pi(\mathrm{d} / 2)^{2}$.

Carotid artery injury assay. For arterial thrombosis studies, mice were anesthetized with ketamine $(100 \mathrm{mg} / \mathrm{kg}$, i.p.)/xylazine $(10 \mathrm{mg} / \mathrm{kg}$ i.p.) and carotid blood flow recorded exactly as previously described (11). After recording baseline blood flow (10 minutes), arterial injury was induced for 1 minute 45 seconds using direct adventitial application of $\mathrm{FeCl}_{3}$, after which blood flow recording was resumed for 30 minutes. Blood flow was estimated as the area under the curve for the 10 minutes immediately prior to or following arterial injury.

Native and recombinant A2. Native A2 was purified to homogeneity from the lungs of control and hyperhomocysteinemic mice as previously described $(62,63)$ and evaluated by $12.5 \%$ reducing SDS-PAGE as well as immunoblot analysis using anti-A1, anti-A2, and anti-A6 monoclonal IgGs. For ligand blotting, extracts ( $1 \%$ Triton X-100 and $10 \mathrm{mM}$ EDTA) of a total membrane fraction (62) were run on $15 \%$ polyacrylamide gels ( $30 \mu \mathrm{g} / \mathrm{lane})$ under reducing or nonreducing conditions. After transfer to PVDF membranes, the blots were blocked ( $5 \% \mathrm{BSA}$ ) and probed with rabbit anti-mouse TPA IgG (American Diagnostica; 1:3,000, 1 hour, $21^{\circ} \mathrm{C}$ ), followed by HRPconjugated donkey anti-rabbit IgG $\left(1: 3,000,30\right.$ minutes, $\left.21^{\circ} \mathrm{C}\right)$. Additional blots were probed with mouse anti-A2 $\operatorname{IgG}\left(1: 2,000,16\right.$ hours, $\left.4^{\circ} \mathrm{C}\right)$, followed by HRP-conjugated sheep anti-mouse IgG (GE Healthcare; 1:2,000, 30 minutes, $21^{\circ} \mathrm{C}$ ). Blots were developed using the ECL reagent (GE Healthcare). Ligand blots were probed with human TPA ( $40 \mathrm{nM}, 16$ hours, $4{ }^{\circ} \mathrm{C}$ ), followed by rabbit anti-mouse TPA, HRP-conjugated donkey anti-rabbit IgG, and ECL. GAPDH served as a loading control. rA2 was expressed in BL21 E. coli as previously described (64).

Plasmin generation assay. As described previously (4), A2 purified from lung tissue of mice fed either the Gly or Met diets was incubated with Glu-plasminogen $\left(100 \mathrm{nM}, 1\right.$ hour, $\left.21^{\circ} \mathrm{C}\right)$, followed by TPA $(10 \mathrm{nM})$ premixed with the fluorogenic plasmin substrate aminofluoromethylcoumarin (AFC-81, $125 \mu \mathrm{M})$. Substrate hydrolysis was measured at 6-minute intervals as relative 
fluorescence units at 400-nm excitation and 505-nm emission wavelengths in a SpectraMax Gemini XS fluorescence spectrometer (Molecular Devices).

Matrigel implant studies. Matrigel plugs containing $100 \mathrm{ng} / \mathrm{ml}$ VEGF-A or $75 \mathrm{ng} / \mathrm{ml}$ bFGF with $100 \mu \mathrm{g} / \mathrm{ml}$ heparin induced roughly equivalent degrees of angiogenesis in normal mice. Plugs containing these growth factors plus varying concentrations of DL-HC, L-cysteine, or L-methionine were placed s.c. over the upper left abdomen and harvested on day 12 as previously described (11). PFA-fixed (18 hours, 4\%), paraffin-embedded sections were stained with hematoxylin and eosin. Cellularity was assessed manually by counting 10 fields per section $(\times 200$ magnification; 10 sections per sample) and by computer-assisted image analysis (Metamorph), whereby cellular nuclear area was expressed as a ratio to total Matrigel.

Microvascular endothelial cell invasion assays. HDMECs (Passage 2; Clonetics) were propagated in M199 containing 10\% pooled human serum, $1 \mathrm{mM}$ L-glutamine, $100 \mathrm{U} / \mathrm{ml}$ penicillin-streptomycin, and $10 \mu \mathrm{g} / \mathrm{ml}$ endothelial cell growth factor (Bionetic Research). Invasion assays were performed as previously described in a double-blind fashion (11) using 25 -mm inserts coated with bovine gelatin ( $2 \mathrm{mg} / \mathrm{ml}$; J.T. Baker Chemical), 1:5 diluted Matrigel (Collaborative Biomedical Products), or $300 \mu \mathrm{g} / \mathrm{ml}$ fibrinogen clotted with $15 \mathrm{mU} / \mathrm{ml}$ bovine thrombin. Inserts were placed in wells containing M199 plus $0.25 \%$ pooled human serum supplemented with VEGF-A $(100 \mathrm{ng} / \mathrm{ml})$.

Corneal pocket assay. Control and hyperhomocysteinemic mice (C57BL/6) were anesthetized by i.p. injection of ketamine $(100 \mathrm{mg} / \mathrm{kg})$ and xylazine (10 mg/kg). Hydron-sucralfate pellets containing bFGF (40 ng) were placed exactly as previously described (11), and erythromycin ointment was applied to both eyes. On day 5 after implantation, the eyes were photographed and neovascular area calculated as described previously $(11,65)$.

Statistics. Pairwise comparisons of mean values for individual groups were evaluated using Student's 1 -tailed $t$ test. $P$ values less than 0.05 were considered significant.

\section{Acknowledgments}

We thank Kaili He, Emil Lev, Guangzhi Sui, LunBiao Yan, and Jing Ling for expert technical assistance. This work was supported by NIH grants HL 42493, HL 67839, and HL 90895 to K.A. Hajjar; HL 46403 to K.A. Hajjar, A.J. Marcus, and M.J. Broekman; and HL 47073 to A.J. Marcus and M.J. Broekman and March of Dimes grant 6-FY05 to K.A. Hajjar. A.J. Marcus is the recipient of a Merit Review Grant from the Department of Veterans Affairs and a grant from the Cancer Research and Treatment Fund. A.T. Jacovina was supported by NIH grant T32 HL 07423.

Received for publication April 20, 2009, and accepted in revised form August 5, 2009.

Address correspondence to: Katherine A. Hajjar, Department of Cell and Developmental Biology, Weill Cornell Medical College, 1300 York Avenue, New York, New York 10065, USA. Phone: (212) 746-2034; Fax: (212) 746-8809; E-mail: khajjar@med.cornell.edu.
1. Hajjar, K.A. 2006. Vascular biology. In Clinical hematology. N.S. Young, S.L. Gerson, and K.A. High, editors. Mosby Elsevier. Philadelphia, Pennsylvania, USA. $123-133$.

2. Cines, D.B., et al. 1998. Endothelial cells in physiology and in the pathophysiology of vascular disorders. Blood. 91:3527-3561.

3. Levin, E.G., et al. 1997. The expression of endothelial tissue plasminogen activator in vivo: a function defined by vessel size and anatomic location. J. Cell Sci. 110:139-148.

4. Hajjar, K.A., et al. 1987. Binding of tissue plasminogen activator to cultured human endothelial cells. J. Clin. Invest. 80:1712-1719.

5. Hajjar, K.A., and Hamel, N.M. 1990. Identification and characterization of human endothelial cell membrane binding sites for tissue plasminogen activator and urokinase. J. Biol. Chem. 265:2908-2916.

6. Hajjar, K.A. 1991. The endothelial cell tissue plasminogen activator receptor: specific interaction with plasminogen. J. Biol. Chem. 266:21962-21970.

7. Hajjar, K.A., Jacovina, A.T., and Chacko, J. 1994. An endothelial cell receptor for plasminogen and tissue plasminogen activator: I. Identity with annexin II. J. Biol. Chem. 269:21191-21197.

8. Gerke, V., and Moss, S.E. 2002. Annexins: From structure to function. Physiol. Rev. 82:331-371.

9. Gerke, V., Creutz, C.E., and Moss, S.E. 2005. Annexins: Linking $\mathrm{Ca} \pm \pm$ signalling to membrane dynamics. Nat. Rev. Mol. Cell Biol. 6:449-461.

10. Cesarman, G.M., Guevara, C.A., and Hajjar, K.A. 1994. An endothelial cell receptor for plasminogen/ tissue plasminogen activator: II. Annexin II-mediated enhancement of t-PA-dependent plasminogen activation. J. Biol. Chem. 269:21198-21203.

11. Ling, Q., et al. 2004. Annexin II is a key regulator of fibrin homeostasis and neoangiogenesis. J. Clin. Invest. 113:38-48.

12. Selhub, J. 1999. Homocysteine metabolism. Annu. Rev. Nutr. 19:217-246.

13. Jacobsen, D. 2001. Practical chemistry of homocysteine and other thiols. In Homocysteine in health and disease. R. Carmel and D. Jacobsen, editors. Cambridge University Press. New York, New York, USA. 9-20.
14. Nygard, O., et al. 1997. Plasma homocysteine levels and mortality in patients with coronary artery disease. N. Engl. J. Med. 337:230-236.

15. Malinow, M.R., Bostom, A.G., and Krauss, R.M 1999. Homocyst(e)ine, diet, and cardiovascular diseases: A statement for healthcare professionals from the nutrition committee, American Heart Association. Circulation. 99:178-182.

16. Pietrzik, K., and Bronstrup, A. 1997. Causes and consequences of hyperhomocyst(e)inemia. Int. J. Vitam. Nutr. Res. 67:389-395.

17. Moat, S.J., et al. 2004. Folate, homocysteine, endothelial function and cardiovascular disease. J. Nutr. Biochem. 15:64-79.

18. Splaver, A., Lamas, G.A., and Hennekens, C.H. 2004. Homocysteine and cardiovascular disease: Biological mechanisms, observational epidemiology, and the need for randomized trials. Am. Heart J. 148:34-40.

19. Markus, H.S. 2007. Genes, endothelial function and cerebral small vessel disease in man. Exp. Physiol. 93:121-127.

20. Ling, Q., and Hajjar, K.A. 2000. Inhibition of endothelial cell thromboresistance by homocysteine. J. Nutr. 130:373S-376S.

21. Hajjar, K.A., et al. 1998. Tissue plasminogen activator binding to the annexin II tail domain: direct modulation by homocysteine. J. Biol. Chem 273:9987-9993.

22. Hajjar, K.A. 1993. Homocysteine-induced modulation of tissue plasminogen activator binding to its endothelial cell membrane receptor. J. Clin. Invest. 91:2873-2879.

23. Hajjar, K.A., and Jacovina, A.T. 1998. Modulation of annexin II by homocysteine: implications for atherothrombosis. J. Investig. Med. 46:364-369.

24. Carmeliet, P. 2003. Angiogenesis in health and disease. Nat. Med. 9:653-660.

25. Risau, W. 1997. Mechanisms of angiogenesis. Nature. 386:671-674.

26. Werb, Z. 1997. ECM and cell surface proteolysis: Regulating cellular ecology. Cell. 91:439-442.

27. Loskutoff, D.J., and Quigley, J.P. 2000. PAI-1, fibrosis, and the elusive provisional fibrin matrix. J. Clin.
Invest. 106:1441-1443.

28. Lijnen, H.R. 2001. Plasmin and matrix metalloproteinases in vascular remodeling. Thromb. Haemost. 86:324-333

29. Farrehi, P.M., Ozaki, K., Carmeliet, P., and Fay, W.P. 1998. Regulation of arterial thrombolysis by plasminogen activator inhibitor- 1 in mice. Circulation. 97:1002-1008

30. Fay, W.P., Parker, A.C., Ansari, M.N., Zheng, X., and Ginsburg, D. 1999. Vitronectin inhibits the thrombotic response to arterial injury in mice. Blood. 93:1825-1830

31. Konstantinides, S., Schafer, K., Thinnes, T., and Loskutoff, D.J. 2001. Plasminogen activator inhibitor-1 and its cofacor vitronectin stabilize arterial thrombi following vascular injury in mice. Circulation. 103:576-583.

32. Kurz, K.D., Main, B.W., and Sandusky, G. 1990. Rat model of arterial thrombosis induced by ferric chloride. Thromb. Res. 60:269-280.

33. Kenyon, B.M., et al. 1996. A model of angiogenesis in the mouse cornea. Invest. Ophthalmol. Vis. Sci. 37:1625-1632.

34. McCully, K.S. 1969. Vascular pathology of homocysteinemia: Implications for the pathogenesis of atherosclerosis. Am. J. Pathol. 56:111-128.

35. Humphrey, L.L., Rongwei, F., Rogers, K., Freeman, M., and Helfand, M. 2008. Homocysteine level and coronary heart disease incidence: A systematic review and meta-analysis. Mayo Clin. Proc. 83:1203-1212.

36. Maron, B.A., and Loscalzo, J. 2006. Homocysteine. Clin. Lab. Med. 26:591-609.

37. Eldibany, M.M., and Caprini, J.A. 2007. Hyperhomocysteinemia and thrombosis. Arch. Pathol. Lab. Med. 131:872-884.

38. Antoniades, C., Antonopoulos, A.S., Tousoulis, D., Marinou, K., and Stefanadis, C. 2009. Homocysteine and coronary atherosclerosis: From folate fortification to the recent clinical trials. Eur. Heart J. 30:6-15.

39. Hassan, A., et al. 2003. Homocysteine is a risk factor for cerebral small vessel disease, acting via endothelial dysfunction. Brain. 127:212-219.

40. Fassbender, K., et al. 1999. Homocysteine in cerebral 
macroangiography and microangiopathy. Lancet. 353:1586-1587.

41. Wong, A., et al. 2006. Hyperhomocysteinemia is associated with volumetric white matter change in patients with small vessel disease. J. Neurol. 253:441-447.

42. Khan, U., Hassan, A., Vallance, P., and Markus, H.S 2007. Asymmetric dimethylarginine in cerebral small vessel disease. Stroke. 38:411-413.

43. Folstein, M., et al. 2007. The homocysteine hypothesis of depression. Am. J. Psychiatry. 164:861-867.

44. Selhub, J. 2008. Public health significance of elevated homocysteine. Food Nutr. Bull. 29:S116-S125.

45. Smith, D.A. 2008. The worldwide challenge of the dementias: A role for $\mathrm{B}$ vitamins and homocysteine? Food Nutr. Bull. 29:S143-S172.

46. Looker, H.C., et al. 2003. Homocysteine as a risk factor for nephropathy and retinopathy in Type 2 diabetes. Diabetologia. 46:766-772.

47. Schwartzfarb, E.M., and Romanelli, P. 2008. Hyperhomocysteinemia and lower extremity wounds. Int J. Low. Extrem. Wounds. 7:126-136.

48. Castro, R., Rivera, I., Blom, H.J., Jakobs, C., and Tavares de Almeida, I. 2006. Homocysteine metabolism, hyperhomocysteunaemia and vascular disease: an overview. J. Inherit. Metab. Dis. 29:3-10.

49. Abahji, T.N., et al. 2007. Acute hyperhomocysteinemia induces microvascular and macrovascular endothelial dysfunction. Arch. Med. Res. 38:411-416.

50. Undas, A., et al. 2006. Plasma homocysteine affects fibrin clot permeability and resistance to lysis in human subjects. Arterioscler. Thromb. Vasc. Biol. 26:1397-1404

51. Colucci, M., et al. 2008. Mild hyperhomocysteinemia is associated with increased TAFI levels and reduced plasma fibrinolytic potential. J. Thromb. Haemost. 6:1571-1577.

52. Sauls, D., Wolberg, A.S., and Hoffman, M. 2003. Elevated plasma homocysteine leads to alterations in fibrin clot structure and stability: Implications for the mechanism of thrombosis in hyperhomocysteinemia. J. Thromb. Haemost. 1:300-306.

53. Todd, A.S. 1964. Localization of fibrinolytic activity in tissues. Br. Med. Bull. 20:210-212.

54. Levin, E.G., and del Zoppo, GJ. 1994. Localization of tissue plasminogen activator in the endothelium of a limited number of vessels. Am. J. Pathol. 144:855-861.

55. Levin, E.G., Osborn, K.G., and Schleuning, W.D. 1998. Vessel-specific gene expression in the lung: tissue plasmingen activator is limited to bronchial arteries and pulmonary vessels of discrete size. Chest. 114:68S.

56. Wojta, J., Hoover, R.L., and Daniel, T.O. 1989. Vascular origin determines plasminogen activator expression in human endothelial cells. Renal endothelial cells produce large amounts of single chain urokinase type plasminogen activator. J. Biol. Chem. 264:2846-2852.

57. Pepper, M.S., et al. 1993. Upregulation of urokinase receptor expression on migrating endothelial cells.
J. Cell Biol. 122:673-684.

58. Wojtukiewicz, M.Z., Sierko, E., Klement, P., and Rak, J. 2001. The hemostatic system and angiogenesis in malignancy. Neoplasia. 3:371-384.

59. Velez-Carasco, W., Merkel, M., Twiss, C.O., and Smith, J.D. 2008. Dietary methionine effects on plasma homocysteine and HDL metabolism in mice. J. Nutr. Biochem. 19:362-370.

60. Kopp, H.G., et al. 2006. Thrombospondins deployed by thrombopoietic cells determine angiogenic switch and extent of revascularization. J. Clin. Invest. 116:3277-3299.

61. Nagashima, M., et al. 2002. Thrombin-activatable fibrinolysis inhibitor (TAFI) deficiency is compatible with murine life. J. Clin. Invest. 109:101-110.

62. Moore, G.M., Goulet, F., and Sartorelli, A.C. 1992. Purification of annexin I and annexin II from human placental membranes by high performance liquid chromatography. Protein Expr. Purif. 3:1-7.

63. Khanna, N.C., Tokuda, M., and Waisman, D.M 1987. Purification of three forms of lipocortin from bovine lung. Cell. Calcium. 8:217-228.

64. Hajjar, K.A., Guevara, C.A., Lev, E., Dowling, K., and Chacko, J. 1996. Interaction of the fibrinolytic receptor, annexin II, with the endothelial cell surface: essential role of endonexin repeat 2. J. Biol. Chem. 271:21652-21659.

65. Kenyon, B.M., Browne, F., and D’Amato, R.J. 1997. Effects of thalidomide and related metabolites in a mouse corneal model of neovascularization. Exp. Eye Res. 64:971-978. 